\title{
O SIGNIFICADO DA SOCIOCOSMOLOGIA NAS HISTÓRIAS DOS KOFA AG: O MUNDO E A VIDA KAINGANG
}

\author{
CÍNTIA MARIA DA SILVA GUISSO ${ }^{1}$ \\ Unochapecó
}

LÚCIA TERESINHA MARCHIORI DOS SANTOS BERNARDI ${ }^{2}$

Unochapecó

\begin{abstract}
RESUMO: $O$ presente trabalho aborda a educação indigena e analisa o significado da sociocosmologia presente na cultura imaterial dos Kaingang, transmitida pelos kofa ag ("velhos") através de histórias, em relação à noção de mundo e de vida desse povo. A pesquisa, desenvolvida na Terra Indígena Xapecó, é de cunho qualitativo, conforme a perspectiva da autoetnografia. O estudo permite inferir que o povo Kaingang reproduz e recria, através de suas histórias, os conceitos fundamentais de organização social, moral e religiosa, salvaguardando princípios e valores que são perpassados através de metáforas e embasados na relação intensa do Kaingang com a natureza e com a espiritualidade.
\end{abstract}

PALAVRAS-CHAVE: Histórias Kaingang; kofa ag ("velhos”); sociocosmologia.

ABSTRACT: The present work addresses the issue of indigenous education and analyses the signification of the sociocosmology present in the Kaingang's ethereal culture, transmitted by the kofa ag ("the elder") through stories, regarding their view of the world and of life. This research, developed in the Xapecó Indigenous Land, is of qualitative nature, according to the perspective of autoethnography. The study allows to infer that the Kaingang people reproduce and rebuild, through their stories, the fundamental concepts of social, moral and religious organization, safeguarding principles and values that are permeated through metaphors based on their intense relation with nature and the spiritual matter.

KEYWORDS: Kaingang stories; kofa ag ("the elder"); sociocosmology.

\footnotetext{
${ }^{1}$ Indígena Kaingang. Mestre em Educação pela Universidade Comunitária da Região de Chapecó (Unochapecó), recebendo apoio como Bolsista Capes. É professora da Escola de Educação Básica Cacique Vankrê, na Terra Indígena Xapecó, em Ipuaçu, SC, Brasil. E-mail: cintiamarcia@ unochapeco.edu.br .

${ }^{2}$ Doutora em Educação Científica e Tecnológica, pela Universidade Federal de Santa Catarina (UFSC), professora pesquisadora do Programa de Pós-graduação em Educação da Universidade Comunitária da Região de Chapecó (Unochapecó). E-mail: lucib@unochapeco.edu.br .
} 


\section{Uma conversa inicial: o povo Kaingang e o contemporâneo}

A pesquisa aqui apresentada foi desenvolvida na Terra Indígena Xapecó (TI Xapecó), localizada entre os municípios de Ipuaçu e Entre Rios, no Oeste de Santa Catarina. É uma Terra Indígena de uso tradicional das comunidades Kaingang, sendo que há também presença Guarani. Nos últimos quarenta anos, da década de 1970 até 2016, muitos trabalhos de pesquisa foram desenvolvidos sobre a TI Xapecó. Pesquisadores não indígenas estudaram o povo Kaingang, sua história, seu território, seu modo de vida, seus costumes, sua organização, seus mitos e suas lendas. Falaram da cosmologia, da educação indígena ${ }^{3}$ e da educação escolar indígena. Como principais autores, podemos citar Ana Lúcia Vulfe Nötzold (2003 e 2004) e Nötzold e Manfroi (2006), Juracilda Veiga (1994, 2000 e 2006), Kimiye Tommasino (1995), Lucí T. M. dos Santos Bernardi (2011), Silvio Coelho dos Santos (1970), Wilmar da Rocha D'Angelis (2012) e Zaqueu Key Claudino (2010 e 2013), que são citados ao longo deste trabalho.

O ideário construído sobre o povo Kaingang da TI Xapecó é importante para delinear e contar sua história de luta; porém, poucas pessoas a conhecem. Assim, registrá-la é resgatar, recontar fatos do passado, contribuindo para o fortalecimento do processo histórico do povo Kaingang. O elemento novo que trazemos nesta pesquisa é olhar essa história pela perspectiva do indígena, inspirado em uma autoetnografia, ou seja, através do registro do próprio indígena, da escuta dos kofa ag, os velhos de nossa comunidade. As histórias contadas por eles são o reflexo do que aconteceu no passado, mas que permeia também o presente.

Sou indígena ${ }^{4}$ e faço parte da etnia Kaingang, batizada com o nome de Rérir, que quer dizer "Pôr-do-sol". Meus pais são indígenas, sempre

\footnotetext{
3 “[...] a educação indígena refere-se aos processos próprios de transmissão e produção dos conhecimentos dos povos indígenas, enquanto a educação escolar indígena diz respeito aos processos de transmissão e produção dos conhecimentos não indígenas e indígenas por meio da escola, que é uma instituição própria dos povos colonizadores". (LUCIANO, 2006, p.129).

${ }^{4} \mathrm{O}$ texto aqui apresentado é um recorte de uma dissertação defendida no Curso de Mestrado em Educação pela Universidade Comunitária da Região de Chapecó (Unochapecó). Pela natureza do trabalho, optamos por escrever na primeira pessoa, para dar voz à pesquisadora indígena, mesmo que com parceria na autoria do trabalho.
} 
viveram junto a nosso povo. Durante toda minha infância, ouvi as histórias de meu povo e continuo ouvindo e recontando essa magia para meus filhos. É uma forma para que os jovens e as crianças da comunidade conheçam um modo de vida um pouco diferente daquele presente nos dias de hoje - aquele que o povo tinha no passado.

Hoje, muito do modo de vida Kaingang assumiu a influência do não indígena. A nova realidade sociocultural passou a ser um grande desafio para nosso povo; é preciso escrever uma história do passado e do presente, como nos coloca Tommasino (1995, p. 238):

Quando os Kaingang referem-se ao passado, e ao modo
como viviam, denominam tal tempo de vãsy ("há muito
tempo") ou gufã ("antigo", "ancestral"), em oposição ao
tempo atual, uri. Essa dualidade temporal situa o vãsy
no tempo em que seus avós ainda existiam e viviam da
caça-pesca-coleta-agricultura e eram povos da floresta.
No outro extremo, situam-se o uri, tempo atual dos
Kaingang. Unindo os dois extremos desse processo, há
um longo período de adaptação, de rupturas, de
reconstrução, de luta, período que, na cronologia
ocidental, já dura 150 anos.

Nessa história entre passado e presente, é essencial a conservação da identidade étnica e cultural do povo Kaingang; por isso, defendo que transitar em outras culturas não nos faz deixar de sermos índios. Essas inquietações constituem o cenário do presente trabalho, que tem como tema a Sociocosmologia do povo Kaingang e a noção de mundo e de vida desses indígenas, cujo entrelaçamento queremos fazer a partir das histórias contadas pelos kofa ag da própria comunidade.

Toda a especificidade de que nossa cultura dispõe é um atributo necessário para uma educação indígena que oportunize à comunidade Kaingang assegurar a proteção dos seus costumes, crenças e tradições. Segundo Nötzold e Manfroi (2006), mantemos um campo rico de informações e explicações sobre o mundo indígena: os velhos são sábios e guardam na memória um amplo acervo de conhecimento adquirido através de lutas, do dia a dia na aldeia.

As histórias Kaingang foram se perdendo a partir do contato com outras culturas. Os kofa ag deixaram de contar essas histórias por falta de interesse dos gir ("crianças"). Sabemos que a maior riqueza da cultura 
e da educação indígena Kaingang está na tradição oral, pois é oralmente que se ditam as leis, as crenças, os costumes, as curas e os remédios naturais. São conhecimentos que vão passando de geração em geração através da oralidade, isto é, dos avós para as mães e das mães para os filhos. Mas, hoje, percebemos que transmitir oralmente não basta: precisamos registrar o que nos é ensinado, tornando-nos escritores da nossa própria história.

\section{Organização social e sociocosmologia}

Diz-nos Luciano (2006) que toda organização social, cultural e econômica de um povo indígena está relacionada a uma concepção de mundo e de vida. Ou seja, há uma determinada cosmologia organizada e expressa por meio dos mitos e dos ritos. A organização social de nosso povo Kaingang se dá em metades exogâmicas, Kamé e Kanhru ${ }^{5}$ - que se opõem e se complementam -, e em quatro seções ou clãs, Kamé e Wonhétky, de um lado, Kanhru e Votor, do outro. Essa divisão não se dá apenas entre os homens e as mulheres, mas também entre os seres da natureza. Por exemplo, o Sol é Kamé e a Lua é Kanhru; o pinheiro é Kamé e o cedro é Kanhru; o lagarto é Kamé e o macaco é Kanhru; a palmeira é Kamé, já seu fruto é Kanhru - e assim por diante.

Veiga (2006) aborda que, na interpretação de Nimuendajú, por terem sido criados pelos "pais fundadores", Kamé e Kanhru, todos os seres da natureza pertenciam às duas metades, com exceção da terra, do céu, da água e do fogo. Do ponto de vista da autora, essa relação é visível até hoje nas plantas e nos animais. Pode-se perceber quando há ligação com Kamé ou Kanhru.

A autora ainda identifica que:

[...] o discurso Kaingang, idealmente, costuma enfatizar com freqüência a complementaridade entre as metades, de um lado, e entre sociedade e natureza, de outro, sublinhando as relações aparentemente simétricas entre opostos, no primeiro caso, e marcando a possibilidade

\footnotetext{
${ }^{5}$ Nos escritos sobre os Kaingang, temos variações como: Kanhru, Kanhuru, Kaĩru, Kanieru, Kadnyerú, Kañerú, Kairu. Utilizo a nominação Kanhru, como se faz na nossa comunidade, termo utilizado no ensino da língua Kaingang na escola.
} 
de relação entre mundos concebidos diferentemente, no segundo caso. Na verdade, este princípio dialético marca continuamente o discurso Kaingang, que aponta para a "aversão e o horror à junção de coisas iguais porque elas são estéreis" e que dissemina a idéia de que "a fertilidade vem da união dos princípios contrários" (VEIGA, 2000, p. 79).

Cada metade tem sua pintura. Os Kamé têm a marca comprida e de cor preta - chamamos de rã téj ou rá joj; já os Kanhru têm a marca redonda e de cor vermelha - chamamos de rã rôr ou rá kutu; e ainda, alguns Kamé têm dois riscos, os rá táktéi.

Também aprendemos, através da tradição oral, que os Kamé estão relacionados ao Oeste e os Kanhru, ao Leste, o que se refere ao surgimento do povo Kaingang. Segundo a história Kaingang, havia uma montanha na qual surgiram dois buracos, um do lado em que o sol nasce e outro do lado em que o sol se põe. Os Kanhru saíram do buraco do lado em que o sol estava nascendo, por isso adquiriram a cor vermelha. Já os Kamé saíram do buraco do lado em que a noite estava chegando, por isso a cor preta. Basicamente, essa é a história, por isso essa relação com as metades Kamé e Kanhru.

Juracilda Veiga traz, em suas pesquisas, registros de relatos de kofa ag sobre nosso modo diferente de viver, ou seja, sobre nossos costumes e nossa origem, nossa relação com a natureza e com os animais. De acordo com a autora:

A origem dos kaingang, os kamé e os kanhru proporcionam uma maneira de classificação abrangente, na qual os seres da natureza, incluindo os seres humanos, possuem valores associados às metades exogâmicas, como forte, fraco, alto, baixo, valente ou medroso. Entendemos que o sol saiu primeiro da terra, depois à lua com os seus descendentes kanhru, pois o sol e a lua eram duas pessoas que pertenciam à mesma metade exogâmica, kamé e kamé. Por serem parentes não podiam se apaixonar muito menos casar, por isso Topé (Deus) fez com que vivessem separados eternamente (VEIGA, 1994, p. 87).

Um elemento cultural importante para nosso povo é o "Ritual do Kiki", ou Kikikoi, também conhecido como "Festa do Kiki". Configura-se 
como o principal ritual do nosso povo, oferecido pelos parentes de um falecido recente, que promovem a quebra de relações entre os vivos e os mortos, possibilitando, assim, a incorporação daqueles no mundo dos mortos. Ao espírito da pessoa, chamado de kumbã, é associado seu nome, considerado a parte imperecível, que continua a existir depois da morte. Já o corpo é a parte perecível, chamada de hã. Para nosso povo, o ser humano é composto por essas duas partes, e as doenças e a morte são ocasionadas pela perda do kumbã - ou seja, o corpo perde seu espírito, que vai embora. No Ritual, destacam-se as relações entre as metades clânicas, pois cada uma delas é chamada para tratar os espíritos dos mortos da outra metade com o fim de liberá-los e permitir-lhes que deixem, finalmente, o cemitério onde estavam confinados desde as suas mortes.

O Kikikoi era realizado por todos os grupos até as primeiras décadas do século passado. Porém, durante o processo de conquista e dominação pelos não indígenas, os Kuiã ("rezadores") foram perseguidos pelos administradores do Serviço de Proteção aos Índios (SPI), e muitos grupos acabaram abandonando a realização do Kikikoi. Na TI Xapecó, o Kikikoi permaneceu 23 anos sem ser realizado, sendo retomado apenas em 1976, com o incentivo dos Padres da Paróquia do município de Xanxerê. Infelizmente, logo deixou de ser praticado, em 19996. O principal motivo do ritual não ser mais praticado é porque muitos kofa ag morreram, e os poucos que restam não podem ensiná-lo para os jovens, pois alguns não sabem mais suas marcas tribais, se são Kamé ou Kanhru. A identificação da marca foi se perdendo e é algo que não pode ser mais resgatado.

\section{A cultura imaterial: aquilo que pode ser sentido}

O conceito de cultura é amplo e dinâmico, usado para mostrar a especificidade e os conhecimentos de um determinado povo. Como afirma o antropólogo Adam Kuper (2002, p. 288), "a cultura está mais em

\footnotetext{
${ }^{6}$ De acordo com registros de Tommasino e Rezende (2000), na TI Xapecó foi realizado o Kikikoi em 1976, com incentivo dos padres Lothário Tuiel e Egon Heck, da Paróquia do município de Xanxerê; em 1978, realizaram outro; nos anos 1980, três ou quatro vezes e, nos anos 1990, o Kikikoi se tornou anual. Conforme informações da comunidade, o último ritual foi realizado em 1999.
} 
voga do que nunca", o que demonstra que esse conceito está presente nos diversos povos do mundo e nos mais variados grupos sociais. Para o autor, a cultura tornou-se um termo politicamente falado, como uma forma de falar sobre identidades coletivas.

Bernardi (2011, p. 101), em sua reflexão sobre a cultura indígena, nos diz:

[...] trago a compreensão acerca da cultura conectada às lutas que estão em jogo no processo de sua apropriação, e sua legitimação nas relações de poder daqueles que a produzem e a reproduzem. O entendimento que estou dando à cultura é de algo que é produzido pelos grupos sociais, algo que não está determinado, consolidado e fechado nos seus significados, mas em permanente disputa pela imposição de significados, considerando a noção de poder a ela associada.

A cultura Kaingang pode ser vista a partir de dois aspectos: o material, como no caso do artesanato elaborado, e o imaterial, que não pode ser observado da mesma maneira, mas que pode ser sentido.

Uma questão que buscamos na cultura imaterial é o sentido da vida. Para tudo há uma explicação, que pode ser obtida através de nossas histórias, ou das danças, das crenças, dos costumes. Como dizem Nötzold e Manfroi (2006, p. 12):

O respeito à diversidade cultural é uma longa caminhada [...] pode ser o primeiro passo desse agradável percurso, sendo um irresistível convite a passear pelos campos da cultura indígena. Conhecimento e respeito andam sempre de mãos dadas, passamos a compreender 0 porquê das diferenças e acima de tudo respeitar as outras culturas quando as conhecemos.

As histórias Kaingang nos fazem passear por essa dimensão cultural, ou seja, mostram um caminho de liberdade, de perseverança para a comunidade. Juracilda Veiga (2006, p. 17), pesquisadora que experienciou anos de convivência permanente com os Kaingang, declara que, durante esse período:

[...] aprendi muito de sua cultura. O suficiente para ter 
certeza de que, por trás de uma roupagem de "povo aculturado", guardam fidelidade a sua cosmologia e seguem as balizas colocadas por sua cultura, como guias seguras no nevoeiro civilizatório em que se transformou a sua terra após o contato.

De acordo com Veiga (2000, p. 241), "os seres míticos marcam o tempo e o espaço na cosmologia de um povo". Isso nos faz lembrar de que as histórias Kaingang são o fio condutor para uma nova concepção Kaingang. Ou seja, é preciso sempre fazer esse balanço entre passado e presente, porque, assim, entenderemos os mistérios da vida Kaingang, mistérios para os quais muitas vezes buscamos explicação e não encontramos.

Para os kofa ag, não há diferença entre história, mito ou lenda. Segundo Veiga (2000), o mito é uma parte da história de um povo. O que podemos perceber nas sociedades ágrafas é que há uma imbricação entre mito e história. Para a autora, tanto o mito quanto a história fazem parte do mundo mitológico, revelando o primeiro motivo do ser indígena. Ambos abordam acontecimentos do passado que ocorrem na criação do povo Kaingang. As pessoas mais velhas não veem essa diferença, pois, para elas, tudo faz parte da história. É nas histórias que buscamos explicações para o que vem acontecendo com os indígenas pelo mundo.

No entendimento de Lévi-Strauss (apud LEACH, 1970), para os povos indígenas, o mito é uma narrativa sagrada. Assim sendo, a qualidade especial da narrativa do mito tem início com uma tradição oral, por sua vez associada ao ritual religioso que contém uma mensagem com a qual os indivíduos se identificam - e até mesmo se apropriam para explicar o porquê de determinadas atitudes humanas. Baseado nesse entendimento de Lévi-Strauss, pode-se dizer que é no mito que encontramos o mistério que envolve a vida e o ser Kaingang.

Parafraseando Nötzold e Manfroi (2006), as lendas fazem parte de um universo para dar explicações e embelezar fatos de maneira maravilhosa, alegre e despojada, revelando, desse modo, as crenças de um mundo habitado, por exemplo, por animais agourentos. Os sons e o canto desses animais denotam uma premonição. Trazemos essas reflexões sobre mito e lenda pois esse debate é fundamental para entender o porquê de pesquisadores não indígenas fazerem essa 
distinção. Ao longo deste texto, vamos empregar a palavra história/histórias sem definir se o relato dos kofa ag é uma lenda ou um mito.

Através das histórias, entendemos as transformações que ocorrem em determinada cultura e por que são importados novos costumes em nosso viver. Fontana (1996, p. 66) coloca que:

\begin{abstract}
A cultura é definida como uma construção histórica, seja como concepção, seja como dimensão do processo social. Ela não é algo natural, não decorre de característica inerente ao homem e nem de leis físicas e biológicas. Ao contrário, a cultura é um produto coletivo da vida humana, enraizado nas condições materiais e sociais de existência, condições contraditórias marcadas pela desigualdade e opressão e pela luta por sua superação.
\end{abstract}

Se, por um lado, nosso povo passou por transformações culturais, seja na própria língua Kaingang, seja nos rituais como o Kikikoi, o lado espiritual não se perdeu: continuou nas famílias. Independentemente de onde possam estar, os traços indígenas são visíveis aos olhos do outro isso é representar a cultura Kaingang.

Nosso desafio é sermos de fato protagonistas de nossa história, registrando o ensinamento ancestral para compartilhá-lo com o mundo, dentro e fora da comunidade. Assim, nossos gir vão entender a luta que os kofa ag travaram para poder guardar todo o conhecimento da história Kaingang, bem como a importância de ouvir os seus relatos, pois é na memória que guardamos os saberes e a nossa própria história. Transmitir as histórias é participar da educação, da formação de cada criança e de cada jovem Kaingang, ajudando-o a ser um verdadeiro guerreiro, podendo torná-lo um líder do povo. Sem sombra de dúvida, transmitir o conhecimento dos kofa ag é um modo de conservar o saber Kaingang.

Os povos indígenas possuem espaços e tempos educativos próprios, dos quais participam a pessoa, a família, a comunidade, sendo a educação assumida como responsabilidade coletiva. E ela acontece em processo: ao longo de sua vida uma pessoa está sempre aprendendo. Ela é viva e exemplar: aprende-se pela participação na vida, observando e agindo (BONIN, 2008, p. 99). 
Essa resistência para assegurar a participação efetiva da comunidade na educação das crianças é feita pela comunidade ela mesma; afinal, não se aprende nada sozinho - a aprendizagem é a continuidade de uma luta, seja pela vida ou pela terra. Nós damos valor à terra, aos nossos costumes, aos ensinamentos dos kofa ag. Sabemos que a continuação dos saberes Kaingang depende dos kofa ag, que detêm o saber tradicional Kaingang. Como nos diz o indígena Claudino (2013, p. 32), "são eles que representam a força da vida e preparam os jovens para a continuação de sua etnia". São considerados bibliotecas vivas do nosso povo Kaingang: sabem de onde vieram, onde estão e para onde vão.

\section{Os caminhos metodológicos e os sujeitos: ensaios de autoetnografia}

O processo cultural das histórias indígenas revela valores espirituais que, muitas vezes, estão ocultos nos mitos, nas lendas transmitidas de geração em geração pelas pessoas mais velhas da comunidade. É por isso que a oralidade é a peça-chave que norteia a educação indígena: são os mais velhos que ensinam, que transmitem conhecimentos milenares, num processo contínuo de fortalecimento do povo indígena. Esta pesquisa investigou as formas de expressão da cultura imaterial do povo Kaingang à luz da sociocosmologia, identificando como as noções de pessoa e de mundo influenciam na organização da comunidade TI Xapecó, a partir de histórias de seus kofa ag.

Num primeiro momento, pensamos em uma pesquisa do tipo etnográfica. Lévi-Strauss define a etnografia como uma prática que consiste na "observação e análise de grupos humanos [...] escolhidos entre aqueles que mais se diferenciam do nosso [...] e que busca restituir, com maior fidelidade possível, a vida de cada um deles" (LÉVI-STRAUSS, 1987, apud KLINGER, 2007, p. 28).

Essa visão é consolidada ao longo da história do Brasil em relação aos povos indígenas, "aqueles que mais se diferenciavam" dos brancos que aqui chegaram. Sempre ocupamos o lugar do "etnografado": sobre 
quem se investiga, quem se descreve, sobre quem se estuda o modo de vida, enfim, o objeto de muitas pesquisas da Academia. A relação colonizador e colonizado estabelece-se também na pesquisa. Hoje, passamos a ser protagonistas de nossa própria história. Será uma nova forma de etnografia? Uma autoetnografia?

De acordo com Bittencourt e Silva (2007), a expressão autoetnografia é utilizada por Mary Louise Pratt em seu livro Imperial Eyes (1992) para designar as representações que os colonizados constroem sobre si mesmos num diálogo com as representações projetadas pelos colonizadores em seus textos etnográficos. Pode-se igualmente utilizar esse termo para designar as versões dos indígenas sobre as histórias de contato com os colonizadores e, ainda, como uma forma de seleção e escrita situada na perspectiva das próprias comunidades indígenas.

A pesquisadora Klinger (2007), também a partir Mary Louise Pratt, afirma que uma forma de entender a autoetnografia é pensá-la como um conceito que abrange desde o momento em que os "etnografados" se tornam autores de estudos sobre seu próprio grupo, até o surgimento das narrativas pessoais escritas por membros de grupos minoritários e a inserção, por parte dos antropólogos, de experiências pessoais dentro dos escritos etnográficos. Assim, classificamos a presente pesquisa como autoetnográfica, o que compreendo como uma investigação na qual uma indígena torna-se autora de um estudo sobre seu próprio povo, segundo a perspectiva de sua própria comunidade.

Como indígena e pesquisadora, procurei registrar histórias Kaingang que fazem parte da cultura imaterial da tradição oral de meu povo, buscando, na nossa origem, a motivação para enriquecer cada vez mais a cultura através da experiência vivida e da troca de saberes com os mais velhos. Na proposta de autoetnografia, minha aproximação com os kofa ag não foi feita a partir de um questionário ou roteiro de entrevista, mas via confraternização, troca de ideias, momento de escuta. As visitas às casas dos kofa ag se repetiram diversas vezes, e em nenhuma delas pedi para me contarem histórias: sempre deixei que surgissem da sua vontade. Isso levou um tempo, porque, na primeira visita, eles sempre ficam desconfiados, até mesmo com o indígena, pois o modo de vida na comunidade hoje é muito diferente do modo de vida dos kofa ag. O nosso dia a dia corrido diferencia-se muito do deles, e, além dos tempos 
distintos, parece que ocupamos espaços distintos também. As conversas foram gravadas e, posteriormente, transcritas. Algumas histórias foram relatadas na língua Kaingang; outras, na língua portuguesa.

A investigação foi desenvolvida com cinco indígenas: a kofa ag Dona Maria Pureza Fétj da Conceição, de 109 anos de idade; a kofa ag Dona Virginia Kanu Cipriano, de 95 anos de idade; a kofa ag Dona Elvira Rãnõ da Luz Santos, de 91 anos de idade; a kofa ag Dona Maria Virginia Nikãj Mendes, de 65 anos de idade; e o Senhor Kambré, de 87 anos. Na próxima seção, apresento um pouco de minha "escuta" nas conversas com os kofa ag. São relatos de histórias entrelaçadas com outras falas; é a memória daquilo que foi ouvido entrelaçada com a experiência vivida. $\mathrm{Na}$ transcrição aqui feita, as histórias contadas são apresentadas na forma original, respeitando as variações linguísticas que caracterizam a fala de cada kofa ag.

Para a análise, foi necessário fazer uma interlocução com outras bibliografias, consultando obras de pesquisadores que escreveram sobre os Kaingang e a TI Xapecó. Destaco, entre eles, Ana Lúcia Vulfe Nötzold e Juracilda Veiga, por reconhecer o diálogo que essas pesquisadoras empreenderam com meu povo e a riqueza de seus trabalhos - que também foram de escuta - com kofa ag que hoje já não vivem entre nós, e o Kaingang Zaqueu Key Claudino, por seus estudos e escritos sobre nosso povo.

Do corpus de histórias registradas e analisadas na pesquisa, selecionei duas para apresentar neste artigo: $A$ vida do índio e Xikré, em língua portuguesa e em língua Kaingang. Se for do interesse do leitor, é possível consultar outras histórias na dissertação da qual se originou o presente recorte (GUISSO, 2016), bem como informações e imagens dos kofa ag.

\section{O ciclo de vida Kaingang: conversando com a kofa ag Fétj}

Voltar à casa da Dona Maria Pureza da Conceição é sempre um privilégio, porque, além de ser uma "biblioteca viva" na comunidade, é minha avó, e com ela aprendo muitas coisas. Certo dia, ela me falou da vida do índio: 


\section{A vida do Índio}

Fia, nóis é paricido cum a taquara, né? Porque a taquara morre mais sempre vai nascê de novo, a pedra já num é insim, né? É mais dura, num tem vida...

Quando nóis caminhamo no mato i vemo pedra perto duma taquara né?

Ela sempre tá se balançando, memo que num tenha vento, né?

Quando uma pedra ta perto duma taquara é porque elas tão discutindo uma cum a otra. A pedra diz que nossa vida divia sê paricida cum a pedra porque num sente dor i vive pá sempre. Daí a taquara diz que tem que se paricido cum a dela porque morre mais vorta sempre, porque o isprito volta numa pranta, num animar ou quando nasce uma criança. Ai a pedra num tem o que dizê, $i$ anssim ficô nossa vida, paricida cum a vida da taquara.

\section{Sãgfa Kãme}

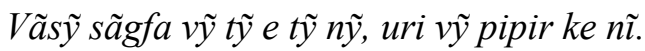

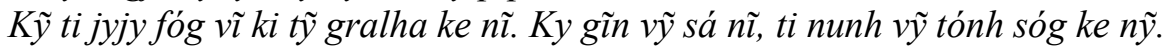

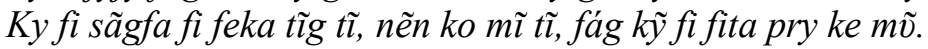

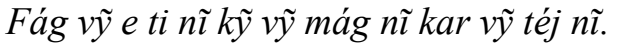

Sãgfa vĩ, sẽsĩ ke nĩ ky tóg vãmém sĩ fág mré sãgfa ke nĩ.

Sẽsĩ tỹ responde ke nĩ inh ve tỹ kórég nĩ, ky tỹ fág ti vĩ ka nãnh keje.

Kur tĩ ã kanhkã vyn ra ã cor ti, sẽsĩ tỹ tév tĩg tĩ.

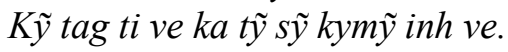

Ky tánh sój kã nãnh mĩ.

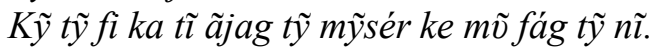

kofa ag Fétj

Em nossa conversa, Dona Maria me disse que "nóis conta da taquara i da pedra, uma história é bastante forte. As pessoa pensa que só o humano tem sintimento, esquece qui quando morrêmo, imo retorná numa pranta ou num passarinho, nunca numa pedra, ela num tem raiz, num tem vida". Assim somos nós e nossas crenças: por mais que um de nossos guerreiros caia, nosso espírito sempre vai ressurgir em uma criança, em uma planta ou em um animal. Faço uso das palavras da Dona Maria quando diz que "a vida é anssin como uma roda, nóis nunca imo pará de lutá". E isso se pode perceber na própria história, quando a taquara diz que "morre, mas logo volta à vida".

De acordo com a tradição indígena, com a morte, o hã, corpo perecível, separa-se do kumbã, o espírito ou alma que continua existindo após a morte. Assim, Dona Maria nos conta que o kumbã volta à vida nas diferentes formas da natureza: humana, animal ou vegetal. Daí a importância do Ritual do Kiki, ou Kikikoi, o culto aos mortos e a crença 
antiga no além-túmulo, pois antigamente os parentes:

Acreditavam na vida além-túmulo, tanto que o feiticeiro avisava o espírito do cadáver quanto aos perigos desconhecidos que poderia enfrentar, mas enfim, chegaria à terra dos mortos tendo como localidade 0 Oeste onde a caça seria abundante e os espíritos velhos rejuvenesceriam (MÉTRAUX apud NÖTZOLD, 2004, p. 66).

Podemos, ainda, observar essa questão nos cânticos entoados no Ritual do Kiki, como cita Borba:

Cagmá, iengrê, oanan eiã ohó iá, engô que tin, in fimbré, ixan na ióngóngue, ianá que nò ò caicá, katô nô ó eká maingvé.

Traducção livre:

Passe com cuidado a ponte. Viva bem com os outros; assim como elles vivem bem, você pode viver. Lá você há de ver muita cousa que já vio aqui em minha terra, assim como o gavião. Teos parentes hão de vir te encontrar na ponte e te levarão com eles para a tua morada (BORBA apud NÖTZOLD, 2004, p. 66).

Hoje, esse ritual não está mais presente na TI Xapecó. Há pelo menos dois motivos principais: alguns dos kofa ag que sabiam as rezas já morreram, e, como é de conhecimento comum na aldeia, se alguém que não souber fazer o ritual tentar fazê-lo, podem morrer muitas pessoas; o segundo motivo é que os poucos que ficaram não podem ensinar as rezas para os jovens, tendo em vista que muitos Kaingang não sabem sua marca tribal, se é Kamé ou Kanhru, devido à influência de outras religiões.

A não identificação da marca tribal decorre, em primeiro lugar, do casamento de indígenas com não indígenas ou com membros de outras etnias indígenas, pois a marca fica misturada (por exemplo, surgem os Wonhétky e os Votor). Também está ligada ao fato de não haver mais obediência à exogamia das metades Kamé e Kaihru na escolha dos noivos e das noivas, que deveria ser feita tendo em vista as metades exogâmicas opostas (antigamente, essa escolha ficava a cargo dos pais). Em segundo lugar, da influência de diversas religiões. Na TI Xapecó, temos mais de vinte igrejas instaladas, entre católicas e evangélicas. Apesar desse 
processo de evangelização dos indígenas já ter se iniciado com os Jesuítas, em nossa Terra, ações nesse sentido começaram por volta dos anos 1990. A transformação cultural e espiritual gerada pela entrada dessas religiões foi muito intensa. Devemos respeitar as religiões, mas sabemos que, com essas interferências externas, o povo Kaingang perdeu muito de sua espiritualidade, de sua relação com a natureza, com a sua sociocosmologia. Vale informar que os kofa ag não frequentam as igrejas, portanto preservam melhor essa relação com a história da espiritualidade indígena.

Como diz minha avó Pureza, "nóis precisava de resposta pá curá doença, nóis ia no mato e tinha parição da planta pá fazê o chá". É a crença de que as qualidades sensíveis das plantas podem ser transferidas aos humanos. Por esse motivo, as pessoas são lavadas com determinados remédios para adquirir deles essas qualidades, como força e resistência, disposição e energia, acuidade visual, destemor, longevidade, etc. "Para isso é necessário falar com o remédio" (VEIGA, 2000, p. 183).

Da experiência com minha avó, lembro que, antigamente, ela me levava para caminhar no mato, porque só os animais do bem é que acordam cedo, então não havia perigo. A gente sentia o perfume das plantas, ouvia o canto dos passarinhos... Ela era guiada por um beija-flor, que indicava as plantas de que precisaria. Hoje, a gente ainda sente o perfume das flores e ouve o canto dos pássaros, mas, mesmo assim, naquela época era diferente. Há coisas que a gente não sabe explicar apenas sente. Uso muito o verbo "falar" no passado quando descrevo o que aprendi com minha avó: não é que ela não fale mais, é que ela perdeu a visão e, então, essas caminhadas no mato não faz mais, mas contar as histórias é com ela mesmo.

Dona Maria conta que "além da vida sê parecida cum taquara, muito dessa pranta nóis têmo na força. Num é quarqué coisa que deixa nóis triste, e na mocidade que parece que nun ficamo véio". Penso que a taquara, por mais que a cortemos, sempre brota em outro lugar, porque a veia mestra fica embaixo da terra. Acredito que a vida seja como uma linha que vai se estendendo quando construímos nossa família, quando nossos filhos, por sua vez, constroem suas famílias, e assim por diante: uns vão morrendo devido à idade, mas a nossa semente fica, que são os filhos. 
Refletindo sobre nossas conversas, ouso inferir sobre o sentido mais forte de seu ensinamento: apesar de todos os desafios enfrentados pelo povo indígena ao longo da história, por mais que tentem dizimá-lo, que derrubem um guerreiro, sempre surgem novos guerreiros para lutar, mostrando que somos um povo de resistência e vida. A taquara é assim: se arrancarmos uma raiz ou cortarmos um galho e o jogarmos em outro lugar, ela vai brotar, mesmo com toda dificuldade; ela leva um tempo para crescer, mas não morre. A pedra já não é assim: se você a jogar onde for, ela fica no mesmo lugar para sempre. Estamos falando, então, da "qualidade" que adquirimos ao nascer: a de ser Kaingang!

\section{Falando dos animais... com os animais}

A relação do meu povo com a natureza é muito forte. O próprio nome "Kaingang" surge de nossa vida na floresta e significa "donos da mata", ou "gente da floresta".

De acordo com Veiga (2000, p. 182), "[...] humanos e não humanos fazem parte de um mesmo ciclo de vida. Tudo que tem vida tem que ser respeitado e tudo o que tem vida um dia vai morrer". A autora ainda coloca, ancorada em Descola (1998), que, para o Kaingang, a relação do homem com a natureza é de reciprocidade, baseada na equivalência entre humanos e não humanos. Essa equivalência é o que permite a troca entre humanos e animais.

O surgimento do povo Kaingang, nas suas diversas versões, apresenta sempre a participação dos animais que pensam, falam e agem como os humanos. Vejamos, em relação à TI Xapecó, a partir dos depoimentos coletados no livro Ouvir Memórias Contar Histórias: Mitos e Lendas Kaingang 7 . Dona Matilde, uma das kofa ag ouvidas para o desenvolvimento daquela pesquisa, relata que "o povo Kaingang aprendeu as danças indígenas com os animais, sendo que os Kamẽ ${ }^{8}$ aprenderam a dançar com o ouriço, e os Kairu com o mico (kajẽr)" (NÖTZOLD e MANFROI, 2006, p. 21).

\footnotetext{
7 Obra na qual participei como autora, juntamente com o grupo de professores da EIEEB Cacique Vanhkrê, na TI Xapecó.

8 As autoras usam essa nomenclatura para Kamé.
} 
Com base nos relatos das pessoas mais velhas da aldeia:

Quando chegaram (Kamẽ e Kanhru) viram seres estranhos, que eram os animais, e perceberam que havia uma comunicação entre eles. Kamẽ e Kanhru não tinham uma forma de se comunicar com eles e a coruja, então, se aproximou e começou a ensinar a língua dos animais. Como eram muito espertos, aprenderam rapidamente a língua dos animais que até hoje falam. Com o passar dos dias, aprenderam muitas coisas. Como o serelepe era um ser muito agitado e então vendo-o dançar, Kamẽ e Kanhru aprenderam a dança do serelepe. Os animais com inveja do serelepe também quiseram ensinar suas danças para eles. Reuniram-se o tatu, macaco, ouriço tamanduá e coruja. Com isso o povo Kaingang cultiva até hoje essas danças [...] (NÖTZOLD e MANFROI, 2006, p. 25-26).

E sobre a da Festa dos Animais:

[...] os dois (Kamẽ e Kanhru) descem a montanha por lados opostos e se encontram embaixo com os animais em festa por o criador ter atendido o pedido deles de criar o ser humano. Havia um problema, eles não se entendiam nem se comunicavam. Eram como crianças (não conheciam a palavra). Os animais acolheram eles e ensinaram a cantar, a falar, dançar (NÖTZOLD e MANFROI, 2006, p. 31).

Dona Divaldina, mais uma das kofa ag com quem conversamos, nos ensina que "a partir de seu nascimento, o nosso povo começa a aprender com a natureza. Os animais têm contribuído muito na transmissão da tradição, das danças, as marcas tribais Kamẽ e Kanhru" (NÖTZOLD e MANFROI, 2006, p. 27).

Esses depoimentos ajudam a compreender que, mesmo que diferentes entre si, permanece a intensa relação que temos com a natureza, o nosso respeito com os animais e a presença deles em muitas das histórias, especialmente os pássaros. De acordo com Veiga (2000), no mito da criação do povo Kaingang se menciona que Kamé e Kanhru criaram os tigres, as antas, as cobras, as abelhas, mas não é mencionada a criação de pássaros e peixes, o que é explicado pela anterioridade dos pássaros (pré-existiam) e pela posterioridade dos peixes (surgiram 
depois, da cabeça de um bugio).

Assim, os pássaros, com seu canto, têm uma forma particular de comunicar-se: eles nos falam. A coruja, por exemplo, que chamamos de sandalha, quando passa cantando e fazendo um barulho que imita como se tivesse cortando um tecido com uma tesoura e voa por cima da casa, anuncia que vai falecer alguém. A kofa ag Dona Emília Pacifico conta que a coruja é bicho sagrado, que se comunica com Deus, e Ele a manda avisar quando uma pessoa vai morrer, para que ela se prepare. "Através da coruja, quando é o Kamê que vai morrer ela grita cinco vezes e quando é o Kanhru que vai morrer ela grita três vezes. Por isso, a coruja é considerada uma ave de agouro" (NÖTZOLD e MANFROI, 2006, p. 35).

Selecionei uma história de pássaros, a do Xikré, para ilustrar essa presença das aves na vida do povo Kaingang.

\footnotetext{
Havia um passarinho chamado Xikré que vivia nas marge dos rio. Voava pelo rio e sentava em cima das pedra, gostava de tomá banho nesse lugar onde ele vive. Quando as pessoa se aproximava, ele voava sobre as correnteza, ele não voa em outras direção.

Tinha um homem que era o dono do fogo, que na língua kaingang é chamado de Pi tãn. Ele tinha uma filha que sempre ia buscá água no rio prá tomá. Um dia o Xikré pensou e disse, “como é que vou fazer para pegá um fogo do Pi tãn. Ah, já sei o que vou fazê, amanhã quando a filha do Pi tãn vié buscá água vou caí na água e fingi que estou quase morrendo, para vê o que ela vai fazê. Sei que ela vai me levá prá perto do fogo prá me enxugá e quando eu tivé enxuto, pego um pedaço de pau de lenha que tivé aceso e vô colocá fogo em alguns capim para que todos possam tê o fogo para se esquentá nas noite fria".

Pi Tãn Kãme

Sikré tỹ sẽsĩ ke nĩ, ti jyjy vỹ pĩ tãn ke mõ, ti tỹ goj kãme tĩg tĩ.

Kỹ tỹ goj tev tĩ sĩ mṽ, kỹ tỹ pó kri nĩ mṽ, kỹ tỹ mroj moroj mũ sér. Kỹ tỹ ṽ ve kỹ tỹ sỹ tinh ke mũ. Kỹ tỹ ṽ sỹ tỹ pĩ kirũr mũ, kỹ tỹ ẽg vĩ to ti jyjy vỹ pĩ tãn ke mũ. Inh pĩ ki tõ ke mõ, kỹ pĩ tãn ti kãsĩn vỹ vyr goj tỹ makãã mṽ ser, kỹ fi tag tỹ goj kron sór, mũ.

Kỹ tỹ ẽg tỹ sikré krégũfar mãn mũ.

Kar tỹ sikré pĩ tõ ken jé mũ kar kurã ke kỹ pĩ makã tĩg sér mũ.

Kỹ tỹ ónmé, tỹ vĩ nĩ goj kuté kỹ ter sór mũ ser, kỹ tỹ goj kuté, kỹ pĩ totãn mũ kỹ tỹ pĩ han mõ sór nĩ nẽn kãmẽ tĩg tĩ, kỹ tỹ inh kusa tỹ vi nĩ, kỹ totãn mũ.

kofa ag Nikãj
}

O fogo é um elemento presente nas histórias de quase todos os povos, existindo muitos mitos contados sobre ele por toda a humanidade. O homem sempre buscou explicar sua origem, quase sempre o relacionando com o poder - como na história de Xikré: há um "dono do Fogo". Por que dono? Porque ele conhecia os segredos do fogo e os guardava para si.

No meu povo, as metades Kamé e Kanhru, pertencentes a lados 
opostos, distintos, com características bem definidas, desempenham papéis ideais de amizade, ajuda mútua, cooperação e complementaridade. Pensando nesses ideais, podemos relacioná-los com a importância da ação do Xikré, de socializar o fogo, vencendo o egoísmo de Pi tãn, que o queria só para si.

Sem o fogo, a única fonte de calor era o sol. Os indígenas sofriam com o frio e comiam todos os alimentos crus. Partilhar o fogo era, então, uma necessidade e um deslocamento de poder.

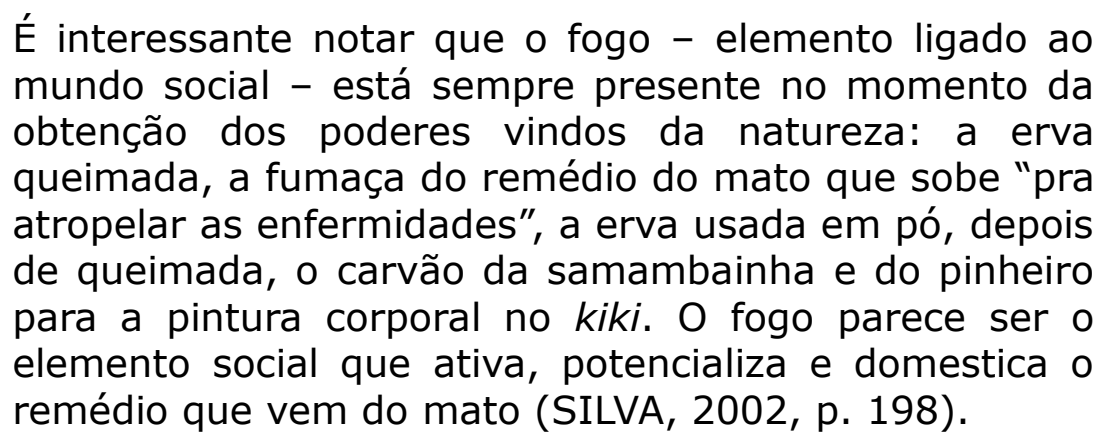

A história do passarinho Xikré mostra esse pensar no outro, ou seja, ele queria que todos tivessem o fogo, não só Pi tãn, que era o dono do Fogo - ele queria a compartilha. Essa é a grande lição da história.

A vida Kaingang também era assim, baseada na compartilha. A gente sabe que, nos dias atuais, é difícil uma pessoa pensar no outro fora do convívio familiar; o egoísmo tornou-se presente na vida do ser humano, e isso não é diferente para os parentes na contemporaneidade. Acredito que a tendência seja piorar, e felizes são os que guardam o valor da solidariedade - como o passarinho Xikré. Percebo que aqueles que sempre moraram na comunidade, que sempre estiveram próximo dos kofa $a g$, têm o costume de compartilhar o que têm, por exemplo: alimentos, roupas, etc.

Já ouvi também a versão da história do Xikré em que, depois que ele rouba a brasa, voa até um pinheiro e acaba derrubando-a, provocando um grande incêndio na floresta, que arde em chamas por muitos dias. Apesar da destruição, foi também um anúncio: índios de muitos lugares viram a chama e foram buscar um tição do fogo para sua aldeia. Assim, houve uma distribuição para todos.

Segundo Tia Maria, "o fogo serve prá limpá a alma, purificá a casa", 
ou seja, permite aos sujeitos se aproximarem, de forma mais leve, gerando melhores relações das pessoas na comunidade. A importância do fogo para meu povo é inquestionável: para além do conforto e do preparo do alimento, é um elemento de proteção espiritual e fortalece o espírito contra doenças. No Ritual do Kiki, é elemento fundamental, como relatam os indígenas: "Os fogos são quatro; dois do Kamẽ e dois do Kanhru. O Kamẽ faz o fogo para Kanhru, e o Kanhru faz o fogo para o Kamẽ" (NÖTZOLD e MANFROI, 2006, p. 29).

Xikré possui uma outra versão, abordada por Veiga (2000) a partir de suas pesquisas com os Kaingang, em que o passarinho escondia a água:

\begin{abstract}
Antigamente, todos os índios eram passarinhos, aí eles foram melar com o Kra (mão de pilão), numa pedra, quando bateram com o kra da pedra ela esbugalhou. Kokoi (beija-flor) descobriu a água na pedra e os outros perguntaram para ele aonde ele achou a água. Ele respondeu que era lá no céu. Eles comiam mel e sentiam sede. Quando eles foram melar de novo viram o Xikré caminhando por lá. O Xikré ouviu o barulho de uma tampa. A água estava fechada; quando Xikré chegou lá e abriu, deu aquele barulho da água que escorreu. Por isso nós temos água (VEIGA, 2000, p. 184).
\end{abstract}

Algumas histórias, com o tempo, também foram sofrendo mudanças, pois cada kofa ag tem seu jeito de contá-la. Nessa versão, o elemento de compartilha é a água, tão vital quanto o fogo, porém colocada desde o princípio à disposição de nosso povo. Essa versão pode ter emergido a partir de momentos de seca, de falta de chuva, pois, na história, Xikré conta que achou a água no céu.

A água (corrente) representa fonte curativa e preventiva, fonte de vida - é um bem que deve estar disponível a todos. É um símbolo de poder espiritual e de força. Lembrando lara9 ${ }^{9}$, cuja história descreve que "então, o espírito das águas transformou o corpo de lara em um ser duplo, onde da cintura para cima mulher, e da cintura para baixo peixe".

Ninguém pode ser "dono da Água", como também ninguém pode

\footnotetext{
9 Iara está descrita como uma lenda em Nötzold e Manfroi (2006, p. 42-43), porém penso que foi inspirada em outras regiões, como a do Norte. Na nossa terra, Iara não é uma mulher: é Mãe D'água, um animalzinho aquático que não é um peixe — se parece mais com uma joaninha. A Mãe D’água é responsável por cuidar da água e manter a vitalidade da fonte.
} 
ser "dono do Fogo". Porém, só a água é finita, e nossos antepassados já compreendiam bem isso. O uso da água, na atualidade, representa relações de poder.

\section{Considerações finais}

As histórias Kaingang são um diálogo entre o passado e o futuro, mediado pelo presente, que podem contribuir na busca de um mundo melhor para a humanidade. São um sinal de respeito pelos mais velhos, de valorização e cuidado com o nosso patrimônio imaterial, um elemento fundante para a educação indígena.

Após concluir este estudo, me permito inferir que as histórias trazem ensinamentos que fazem parte da vida Kaingang, explicando fenômenos e fatos que ocorreram no passado, as relações entre pessoas, as relações do homem com a natureza. Penso que nosso povo reproduz e recria, através das histórias (e também dos rituais), os conceitos fundamentais de organização social e moral, centralizados nas metades exogâmicas Kamé e Kanhru. Através das histórias, ao longo do tempo, nosso povo compreendeu e representou a sociedade, salvaguardando e impondo princípios e valores, possibilitando regras práticas para a orientação dos indígenas.

Esses princípios, valores e regras perpassam as histórias através de metáforas, exemplos e reflexões embasados na relação intensa do Kaingang com a natureza, os animais e as plantas e com a questão espiritual. Sabemos que hoje não é mais como antigamente, mas o pouco que ainda existe conserva o nosso lado espiritual. Precisamos reservar um tempo para sentar embaixo de árvores, ouvir o canto dos pássaros, sentir o perfume das plantas: isso alimenta o nosso espírito, nossa relação com a natureza e nos prepara para as relações com a própria sociedade.

Assim, compreender essas histórias pode ser uma forma de melhorar nossa vida nos dias de hoje, pois elas nos ensinam valores como a solidariedade, o amor, o respeito à ideia do outro - tudo isso fica guardado nas histórias. Porém, um dos pontos altos desta pesquisa é indicar que quem conta e quem escuta uma história tem sempre de fazer 
parte dela, para que possa entender os ensinamentos por ela transmitidos e empregá-los na vida.

Por fim, quero evidenciar que a relação que se pode estabelecer entre um indígena pesquisador e os sujeitos da sua comunidade surge como um novo caminho para conquistar um espaço na sociedade brasileira, rompendo paradigmas preconceituosos em relação aos indígenas: passamos a assumir um novo papel, pesquisando nossa própria cultura. Isso significa que novas formas de pesquisar emergem, e a relação historicamente estabelecida entre pesquisador colonizador e pesquisado colonizado sofre profundas modificações.

\section{Referências bibliográficas}

BERNARDI, Lucí T. M. dos S. Formação continuada em matemática do professor indígena kaingang: enfrentamentos na busca de um projeto educativo. 2011.271 f. Tese (Doutorado em Educação Científica e Tecnológica) - Florianópolis, Universidade Federal de Santa Catarina, [2011].

BITTENCOURT, Circe M. F.; SILVA, Adriana. Perspectivas históricas da educação indígena no Brasil. In: KLINGER, Diana (Org.). Escritas entre si, escritas do outro: o retorno do autor e a virada etnográfica. Rio de Janeiro: 7 Letras, 2007. p. 63-81.

BONIN, Iara. Educação escolar indígena e docência: princípios e normas na legislação em vigor. In: BERGAMASCHI, Maria Aparecida (Org.). Povos Indígenas \& Educação. Porto Alegre: Mediação, 2008. p. 33-48.

CLAUDINO, Zaqueu Key. Educação indígena em diálogo. Pelotas: Universitária, 2010.

A formação da pessoa nos pressupostos da tradição: educação indígena kaingang. 2013. 115 f. Dissertação (Mestrado em Educação) - Porto Alegre, Universidade Federal do Rio Grande do Sul, [2013].

D’ANGELIS, Wilmar. Aprisionando sonhos: a educação escolar indígena no Brasil. Campinas: Curt Nimuendajú, 2012.

DESCOLA, Philippe. Estrutura ou sentimento: a relação com o animal na Amazônia. Mana, Rio de Janeiro, v. 4, n. 1, p. 23-45, 1998.

FONTANA, Roseli A. Mediação pedagógica na sala de aula. São Paulo: Autores Associados, 1996. 
GUISSO, Cintia Marcia da Silva. O significado da sociocosmologia nas histórias dos kofa ag: o mundo e a vida kaingang. 2016. 88 f. Dissertação (Mestrado em Educação) Universidade Comunitária da Região de Chapecó, Chapecó, [2016].

KLINGER, Diana. Escritas entre si, escritas do outro: o retorno do autor e a virada etnográfica. Rio de Janeiro: 7 Letras, 2007.

KUPER, Adam. Cultura: a visão dos antropólogos. Bauru: Edusc, 2002.

LEACH, E. As ideias de Lévi-Strauss. São Paulo: Cultrix, 1970.

LUCIANO, Gersen dos Santos. O índio brasileiro: o que você precisa saber sobre os povos indígenas no Brasil de hoje. Brasília: Ministério da Educação, Secretaria de Educação Continuada, Alfabetização e Diversidade, LACED/Museu Nacional, 2006.

NÖTZOLD, Ana Lucia V. Nosso vizinho kaingáng. Florianópolis: Imprensa Universitária da UFSC, 2003. 2004.

O ciclo de vida kaingáng. Florianópolis: Imprensa Universitária da UFSC,

NÖTZOLD, Ana Lucia V.; MANFROI, Ninatosa M. (Org.). Ouvir memórias, contar histórias: mitos e lendas kaingáng. Santa Maria: Palotti, 2006.

SANTOS, Silvio Coelho dos. A integração do índio na sociedade regional: a função dos postos indígenas em Santa Catarina. Florianópolis: Ed da UFSC, 1970.

SILVA, Sergio Baptista da. Dualismo e cosmologia Kaingang: o Xamã e o domínio da floresta. Horizontes Antropológicos. Porto Alegre, v. 8, n. 18, p. 189-209, 2002.

TOMMASINO, Kimiye. A história dos Kaingang da bacia do Tibagi: uma sociedade Jê Meridional em movimento. 1995. 383 f. Tese (Doutorado em Antropologia Social) São Paulo, Universidade de São Paulo, [1995].

TOMMASINO, Kimiye; REZENDE, Jorgisnei Ferreira de. Kikikoi - Ritual dos kaingang na área indígena Xapecó/SC: registro áudio-fotográfico do ritual dos mortos. Londrina: Midiograf, 2000.

VEIGA, Juracilda. Organização social e cosmovisão kaingang: uma introdução ao parentesco, casamento e nominação em uma sociedade Jê Meridional. 1994. 220 f. Dissertação (Mestrado em Antropologia Social) - Campinas, Universidade Estadual de Campinas, [1994].

Cosmologia e práticas rituais kaingang. 2000. 304 f. Tese (Doutorado em Antropologia Social) - Campinas, Universidade Estadual de Campinas, [2000].

Aspectos fundamentais da cultura Kaingang. Campinas: Editora Curt 
Guisso e Bernardi - O significado da sociocosmologia nas histórias dos kofa ag...

Nimuendajú, 2006.

Recebido em: 25/04/2017 * Aprovado em: 12/10/2017 * Publicado em: 31/12/2017 